\title{
Illustration of Cultural Attributes in China Wushu Routine
}

\author{
Shiliang Yan \\ College of Physical Education, Dezhou University \\ Dezhou 253023, Shandong, China \\ E-mail: tyxys1@163.com
}

Received: December 3, $2010 \quad$ Accepted: December 25, 2010 doi:10.5539/ass.v7n5p166

\begin{abstract}
Wushu is the traditional national sports item with the greatest reputation. Its routine pattern is not simple listing and overlying of movements, but crystallization of Chinese people's artistic creativity and unique thinking mode, which reflects wisdom and ideal pursuit of Chinese people. This article is going to give an illustration to the several cultural attributes implied in Wushu routine and disclose profound connotation of routine culture of Chinese Wushu.
\end{abstract}

Keywords: China, Wushu routine, Cultural attribute

\section{Introduction}

Production of Wushu routine is the necessary outcome under the influence of Chinese traditional culture. From the perspective of the geographical environment, China is located within a semi-closed and highly stable continental terrain, which has great distinction nations across the western Mediterranean countries. From the perspective of production means of goods and materials, Chinese culture is rooted on the basis of agricultural society. And the small-scale peasant economy in the feudal society has its history for several thousand years in China, which has great difference from the nomadic people in Central Asia and Western Asia and the Sea People with relatively developed industrial and commercial industries. From the perspective of the social structure, the patriarch system has become an important bond to maintain the society in the long history of China. The dictatorial system in China continued for more than two thousand years in China, which is rare in the history of the world. It is just due to influences and restraints of the above particular natural and historical conditions that enabled Wushu routine which was born in under the Chinese cultural atmosphere to have its particular image, poetic, harmonious, ethical and aesthetical attributes.

\section{Image and poetic attribute of routine movements}

Movement is the basic unit of routine system and is the entry point for us to analyze the routine. The routine uses movements to describe image of wrestle. Considering the movement structure of the routine, it is based on attack and defense, combined with advancing and retreating, virtuality and reality, dodging and forwarding, jumping and moving. Without attack and defense, there would not have had Wushu. The routine reflects an ideal stylized and versatile means of wrestle. Different sorts of fists and schools all have certain distance from actual combat more or less which is refining and abstracting of wrestling. This kind of abstractness is just as a Chinese character in the eyes of Mr. Qian Mu, which although is a kind of "pictographic character", still it rapidly goes within the scope of "image" and "meaning". Chinese characters often don't depict a specific objective thing, but often describe an image and meaning in an abstract way (Qian Mu, 1994). In the meanwhile, the abstract description can not go without detailed image. Mr. Teng Shouyao termed "the abstract thinking combined with the concept of imagination" as "concrete abstractness" (Nie Zhenbin, Teng Shouyao \& Zhang, Jiangang, 1997). Different from the "purely thinking abstractness" in western aesthetics which "conducts thinking activities on the basis of abstract concept by casting off concrete property", this kind of "image" and "meaning" which can not go without concrete image reflects a major characteristics of Chinese ancient aesthetics. Therefore, routine describes image of wrestling with movement and is not satisfied with similarity in forms, but is aimed to manifest the dynamic feature, imposing manner and artistic conception of wrestling and "symbolize" the movement of image of wrestling. Thus, drilling of Wushu routine is performance of the image of wrestling, not real fighting and attacking, but surpassing real fighting and attacking.

"Concrete abstractness" of Wushu routine in wrestling also exhibits characteristics of aesthetics and imagination. There are some people who believe that Chinese culture has the tendency to be developed from skill to artistry. 
For instance, the process originally supposed to take in nutrition was developed to pursuit of "color, fragrance and taste" in the style of cooking in China. The writing originally supposed to exchange ideas and convey meanings was sublimated to search and pursuit of calligraphic aesthetics in form, soul and meaning in the Chinese land. Furthermore, the teapot originally supposed to be used to drink water was unexpectedly derived to appreciation of its texture, model and acoustics in Chinese culture. China is a country of poetry, which not only has the Songs of Chu, the poetry of the Tang Dynasty, the Chinese Song Poems and Yuan Qu, but had Wushu routine that, in a manner of speaking, is a sort of poetic defense and offense technique so far as the movement property of the routine is concerned. According to the view of Hegel about alienation, alienation of Wushu routine on practicality is the necessary development of an object, which is like a dead birthmark that is branded on a body and accompanies with the body all one's life. Wushu routine was originally supposed to describe wrestling and was practical pursuit in wrestling, or was for memory and heritage. However, it was gradually developed to imagination in wrestling and portrayal of beauty.

\section{Harmonious attribute of the technical target of Wushu routine}

Technical target is the route sign of routine movement and is the evaluation sign of the quality of routine movement.

The overall target of competitive sports in western countries is "higher, swifter and stronger". Its evaluation standard on competitive events in technical projects in Southern America is standardization, difficulty, smoothness and stability. Although it has requirement on harmony, it is absolutely not the primary. Quite different, Chinese Wushu puts in harmony at the first place in the traditional Wushu.

From the perspective of quality of Wushu movement, its ultimate target is not standardization, but harmony (entire harmony). It requires each movement to attain harmony and unification of upper and lower and internal and external part of the body with movement of the body, such as "six harmony of internal and external body", "three harmony of internal body" and "harmony of external body" --- harmony of hand with foot, harmony of elbow with knee, harmony of shoulder with hip, harmony of heart with intention, harmony of intention with breath, and harmony of breath with strength. Considering the strength of movement, harmony is still required. It requires each movement to concentrate on one point by mobilizing all strength of the body, and meanwhile, it pursues tamper force with mercy and integration of lightness and heaviness. "The root lies in the foot, all starts from the leg, waist is the major part and the finger decides the form", etc. Considering the movement and connection of movements, still harmony is what is pursued. An organic unification is realized between movement and movement in that "connection of meaning with break of form, connection of breath with break of strength and changing and concluding". From beginning to end, this is a complete process, like a long painted picture with ups and downs of surging river water, which flows down vigorously. Considering the mode of movement, it is required that movements with different properties should be harmonious in defense and offense, advance and retreat, ups and downs, fastness and slowness, spirit and appearance, falsehood and reality, opening and closing, (pattern) tortuous and strew at random. Considering the requirement of movement, it requires "hand is the top priority for short-hilted broadsword and step is the top priority for double-hilted broadsword", and "eyes move with the hand and eyes focus with force", etc. Furthermore, "once an expert practices Wushu, we know whether he has or not". Here, "has" means "whether one has the nature of the Wushu routine and whether one has harmony of physical movements". The so-called "firstly, stretching of the hand, and then, forwarding of the step" means that every gesture and motion has to achieve high harmony of ups and downs, internal side and external side, appearance and expression, and body and the four limbs. The value orientation is coordinated development of internal side and external side, the body and the practicality and boxing and accomplishment, etc. The approach for exercise is that "one exercises the muscles, bones and skin outside and exercises the breath inside", "exercise of the physical form to get harmonious with the external appearance and exercise of the breath to enrich the internal side", and "exercising to relax the breath, exercising the breath to return to spirit and exercising spirit to return to virtuality", which all reflect that the ability of harmony is the highest state of the traditional Wushu. Once the movement gets harmonious, then the state of "motion as a wave and silence as a high mountain" is attained and audience can be aroused in infinite association, such as, "as light as a leaf, as heavy as iron, as fast as wind and as slow as an eagle", and "appearance like a flying dragon, eyes like an ape awaiting, sitting like a tiger and turning like an eagle hovering", etc. Thus, the ultimate target of the traditional Wushu routine is neither to gain victory, nor not "higher, swifter and stronger", nor "beat a cattle to death by one fist", but the entire harmony of the body. This is the so-called "when one exercise boxing for thousands of times, his power will be manifested automatically". Harmony --- the technical target of Wushu routine is what routine differs from the culture of sports in western countries, and is also what should not be ignored in the current development of Wushu routine. 


\section{Ethic attribute of technical connotation of Wushu routine}

Surveyed from the perspective of science of culture, as a sort of technique, what is reflected behind Wushu routine is the brilliance of Chinese traditional culture. Then, where is the cultural foundation of Wushu culture? Feng Youlan, a Chinese philosopher said, "Foundation of Chinese culture is ethics, but not religion". In the history of China, what has occupied a dominant position is a kind of ethics which seemed to be religion --Confucian culture and Taoism culture (namely, culture of ethics and culture of nature).

The culture of nature which originated from Taoism advocates vitality of Yin and Yang in movement of Wushu routine through "law of nature" and "theory that man is an integral part of nature". In terms of the theory of boxing, culture of nature confirms the theory of Tai Ji, the Eight Diagrams and generation-inhibition in five elements as its guidance. In terms of technical style, law of nature embodies analogy that "dog flees as a cat and rabbit and eagle roar", etc. In practice of Wushu, law of nature calls for initiative combination of the rule of natural law, which is manifested as pursuit in "nature of movement and theory that man is an integral part of nature", such as, "boxing as shooting star and eye as electricity, waist as serpent and step as being sticked". In the aspect of technical method, law of nature no long pursues the purpose of making one cripple and fatal as in the battlefield, but is regarded as experiencing beauty of defense and offense wrestling and surpassing defense and offense. In the aspect of boxing category, law of nature "obtains objects in a far distance and obtains oneself in a nearby place", and generates a kind of achievement as in bionics, that is, pictographic boxing, such as boxing of talons of a falcon, boxing of locust and boxing of monkey, etc.

The social ethics which originated from virtue and morality of Confucianism evolved and modified the technique that sent out cruel smell at the very beginning into "struggle of gentlemen" with "technique of merciful men" and embodied the moral constraints on those who practice Wushu through "practice of morality". In the aspect of influences of personality, there had not been a little bit rudeness, inurbanity or cruelty" (Gu Hongming, 1996). In the aspect of wrestling attitude, "when one looks, one is just like a woman who always makes trouble and when one struggles for something, one is like a frightened tiger". In the aspect of state of mind, one shows respect to Taoism and those who advocate Taoism. In terms of the facial expression, it was required "full of spirit inside and peace outside", and "surging inside but stability outside", etc. In terms of technique, it displays the principle of "that's enough" in wrestling and the strategy of "giving up one's own views and following others". In terms of behavioral standard in Wushu, one should present the moderate idea of "comfortable and impartial", which fully reflects that, just like other parent culture, Chinese Wushu is a sort of culture that does not favor expedition and is a sort of introverted culture which improves itself. For example, when one practice Wushu, one should choose the time and the position and adapt to the solar terms. One should cultivate his will of power, and "carry out training in the coldest and hottest parts of the year" to adapt to the nature. In practice of Wushu, one ought to collect his breath and relax his breath, but should not have a labored breathing, and should follow the physiological rule of the human body. Changes of a movement are particular about opposition of Yin and Yang, which are complementary, such as, silence in movement and movement contained in silence, reality in virtuality and virtuality returning to reality. The dialectics in philosophy is reflected in the various changes in defense and offense and in advance and retreat. Compilation of a movement pursues alteration of fastness and slowness, well-proportioned, rapid movement and stable silence, which really indicates that compilation and performance of the Wushu routine has attained a perfect state.

\section{Aesthetic attribute of routine drilling}

As a sort of aesthetic measure of value, standard often constitutes the highest target of aesthetics. It is gradually formed on the basis of accumulation of long term aesthetic perception experiences for several times. Once a scholar said, "Western countries have the tendency to technicalize arts and China has the tendency to make technique artistic", which deserves great taste. The author of this article has ever attempted to make an analogy between Wushu and calligraphy from the two perspectives of "structure" and "conveying meaning and facial expression", and make a comparison of the comparative beauty of Yin and Yang with the external physical beauty and beauty of strength in the aesthetic concept of western countries. He revealed that, Chinese Wushu concentrated more on beauty of artistic conception and beauty of artistic imagery and was particular about "connection of meaning with break of appearance, connection of strength with break of force and vividness of artistic conception", etc.(Qiu Wangxiang, 1993). Here, the author further made interpretation from the beauty of calligraphy and beauty of Wushu routine.

Just as writing which is originally to convey the ideas and feelings is sublimated to calligraphy, routine is also the sublimation of wrestling, which both are the outcome of making practical technique artistic. Writing with black characters on white papers have had changes of being thick and thin, being dull and smooth and being 
sparse and dense, etc. Wrestling which is originally practical also has such procedures of movement and silence, fastness and slowness, heaviness and slightness, ups and downs, largeness and smallness and turning around, etc. The feature of appreciation of Chinese calligraphy has far exceeded its practical applicability. Its peculiar beauty of line resorts to the curve movement and spatial structure of the line and manifests all kinds of physical postures, kinetic potentials and emotions and interests, which is the particular aesthetic interest of Chinese people. Wushu routine is not simple combination and accumulation of single movement, but is exactly the outcome of wisdom of those who practice Wushu. Likewise, Wushu routine discloses particular movement beauty in the process of drilling and leaves its audience with beautiful inspiration.

Wushu is just like a number of independent characters, with changes of "inclining and covering". Routine is just a calligraphy works, which has the joy of "linking" and "connection of meaning with break of writing". Calligraphy is solidified Wushu routine and drilling of Wushu is creation of dynamic calligraphy. Calligraphy has its particular writing tools, namely, pen, ink, paper and ink-stone. Likewise, drilling of Wushu also has such routines as knife, gun, sword and stick, which are held as instruments. Wushu and calligraphy both have clear-cut Chinese artistic characteristics. "Writing" of calligraphy is not totally to convey the meaning and communicate the thoughts, but is also a kind of poetic works. Likewise, refining and imagining of Wushu routine in attack, defense and wrestling is also poetic works. In its opening, developing, changing and concluding, Wushu routine has its chapter of rhythm, melody of rhyme, rise and fall of physical posture and ups and downs of temperament, and it is a poem of movement.

Delicacy of calligraphy lies totally in the artistic conception and breath, which is not infected with concrete objects in the vulgar world at all. Artistic conception is integration and penetration of the subjective emotional appeal and objective natural scenery manifested by artists in their reflecting all things in the world with their heart and is crystallization of emotion and scenery (Xi Yelan \& Peng Feng, 1996). Thus, the Chinese martial artist Mr. Cai Yunlong pointed out from the perspective of a Wushu performer that, "Only if we place ourselves in an occasion filled with fights, can we perfectly manifest the movement of Wushu routine." From the perspective of a Wushu performer, only if one "reads aloud" with rich facial expression and behaves as if he is personally on the scene, is it likely to embody artistic processing of Wushu routine on movement of wrestling. Or in other words, only a "battlefield" set under one's bottom of heart and manifested as an artistic conception can enable Wushu performers to present a scenery of wrestling with concrete and tangible movement. Deployment and conception of excellent movements of fists and understanding and expression of excellent Wushu performers in drilling movement and Wushu routine present us a scenery of defense and offense, build an atmosphere of wrestling with defense and offense and finally touch the aesthetic heart string of the audience and the infinite association with different opinions. For instance, after having seen the sword dance by Gongsun Daniang, Zhang Xu, the calligrapher in Tang Dynasty, absorbed the cadence strength and posture dance in the dance and improved his calligraphy.

\section{Conclusion}

Wushu routine was formed and development in the Chinese land which is not out of coincidence. The particular geographical environment of China formed characteristics of farmland economy and river culture. Chinese people pursued stability and peace and formed the great political pattern of unification. Philosophical ethics created under this pattern formed the value and practice of human being who pursued self improvement of the actual life, paid attention to the holistic thinking, looked back upon themselves and focused on continuity of the family blood and cultural features of experiential heritage. In terms of the movement structure and technical target of Wushu routine, the peculiar Chinese traditional culture attribute was brought into prominence. We ought to attach great importance to cultural pursuit in Wushu routine and come to profound knowledge in the realistic significance and historical mission it burdens.

\section{References}

Gu, Hongming. (1996). Spirit of Chinese People. Haikou: Hainan Publishing House.

Nie, Zhenbin, Teng, Shouyao \& Zhang, Jiangang. (1997). Survival of Arts. Chengdu: Sichuan People's Publishing House.

Qian, Mu. (1994). Introductory Theory of Chinese Cultural History. Beijing: The commercial Press.

Qiu, Wangxiang. (1993). Intelligence Training of Wushu Athletes. Shanghai: China Sports Coaches, (2):19.

Xi, Yelan \& Peng, Feng. (1996). Collected Works of Zong Baihua. Tianjin: Tianjin People's Publishing House. 